\title{
Powering and Cooling of a Server Room Using a Hybrid Trigeneration System
}

\author{
L. Petrucci, G. Fabbri, C. Boccaletti, and A. J. M. Cardoso
}

\begin{abstract}
This paper analyses the potential of feeding a Server Room through a hybrid trigeneration plant supplying electricity and cooling. The system is made up of a solar concentrating collector, combined with a single stage lithium bromide absorber machine. Such a system is able to provide the three energy vectors required according to the size and the characteristic of the load. Models of the main components have been developed using Simulink and different operating conditions are considered and simulated in a practical application. The results obtained confirm the validity of the proposed hybrid trigeneration system, highlighting the need of different and innovative ways to generate power locally in Distributed Generation (DG).
\end{abstract}

Index Terms-Absorption machine, concentrating photovoltaics, distributed generation, trigeneration.

\section{INTRODUCTION}

The highly growing term tertiary sector involves a large amount of non-residential buildings that are heavy energy consumers as e.g. hotels, hospitals, commercial and public buildings etc. Therefore, the tertiary sector can receive substantial benefits from the extensive utilization of trigeneration technologies, particularly in the Mediterranean region, where due to climatic conditions, absorption cooling can be applied for many hours per year.

A trigeneration plant is a plant with the ability to produce heat, cooling and mechanical (electrical) power simultaneously and is often referred to as a Combined Heat, Cooling and Power (CHCP) plant.

A conventional trigeneration plant requires specific equipments generating both electricity and hot water (or steam) with the latter feeding a chemically driven. The most obvious areas for the application of trigeneration systems are offices, hospitals and the hotel and catering sector having a heating demand in winter and a cooling demand in summer. A particular application is the powering of Information Technology (IT) equipments. The use of IT has become crucial to the functioning and the management of pivotal activities in the buildings.

Manuscript received September 1, 2012; revised November 15, 2012. This work was supported in part by the Portuguese Foundation for Science and Technology (FCT) under Project No. SFRH/BPD/46224/2008, Project No. SFRH/BPD/65591/2009 and Project No PTDC/EEAEEL/114846/2009.

L. Petrucci and G. Fabbri are with the Instituto de Telecomunicações Department of Electrical and Computer Engineering, Pólo II - Pinhal de Marrocos, P3030-290, Coimbra, Portugal (e-mail: gianluca.fabbri@co.it.pt).

C. Boccaletti is with the Department of Astronautics, Electrical and Energetic Engineering, Sapienza University of Rome, Rome, Italy (e-mail: chiara.boccaletti@uniroma1.it).

A. J. Marques Cardoso is with the Department of Electromechanical Engineering, University of Beira Interior, Covilhã, Portugal, and also with the Instituto de Telecomunicações (e-mail: ajmcardoso@ieee.org).
Until recently, the amount of power consumed by Electronic Data Processing (EDP) devices in the buildings was not regarded as important by either users or manufacturers, even though PCs, computer monitors and printers are big energy eaters and represent a major portion of the power consumed within the services sector. In local networks, devices at work desks account for about $60 \%$ of the electricity consumed, followed by servers $(25 \%)$ and switching equipment (15\%). Fig. 1 shows typical power consumption and energy usage of various IT data centre components, including servers, storage, networks and cooling [1].

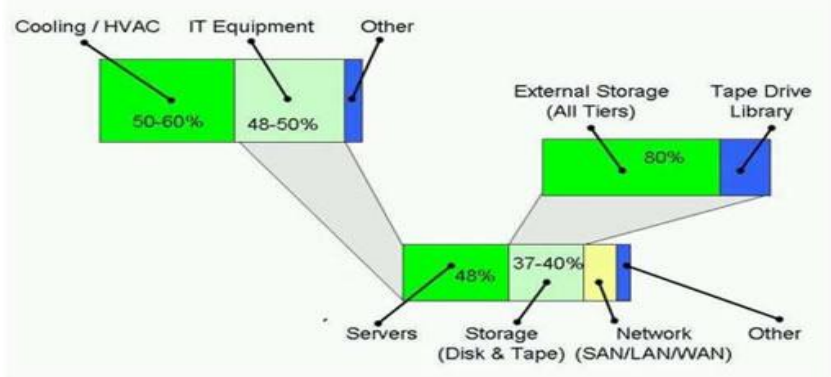

Fig. 1. Average IT data center power and cooling energy consumption.

Previous researchers [2] have shown how energy consumption related to IT activities can dramatically affect the energy bill of an industrialized nation. The necessity to cope with the high heat emissions and electrical consumption of an IT application can be successfully addressed by the adoption of a trigeneration system, which is one of the most efficient way to generate simultaneously heat, cool and power. In this paper a trigeneration system concept based on a novel Concentrating Photovoltaic and Thermal (CPVT) subsystem for the production of heat and power and a Single Stage Lithium Bromide Absorber Machine (SSLBAM) for the production of cold have been simulated and evaluated. Models of the CPVT and of the SSLBAM have been realized in the Matlab Simulink environment and used for the simulation of the system in a practical application. The application regards the powering and cooling of the IT server room of a company located at the last floor of a building with the possibility to use the rooftop surface to install the CPVT.

\section{Miniature Concentrating PV AND AbSORPTION MACHINE: THEORY AND MODELING}

The system under analysis combines the use of a novel Miniature Concentrating Photovoltaic and Thermal (MCPVT) source with an absorption machine unit. The MCPVT is a new approach with promising prospects to the use of solar energy as CHP unit [2]. In contrast to PV/thermal (PV/T) flat 
collectors, the heat from an MCPVT collector is not limited to low-temperature applications and can be used to feed an absorption machine producing both electrical and thermal energy, which can be supplied to a nearby consumer. The two technologies are briefly described in the following subparagraphs.

\section{A. Concentrating $P V$}

The solar concentrator is a renewable energy technology with promising perspective in the field of cogeneration. Kribus et al. [3] have studied an MCPVT equipment which can attain above average levels of electric power by using an array of high efficiency multijunction cells hit by concentrated solar rays. This device concentrates sunlight about 500 times, so that the PV cell area is greatly reduced. The high temperature reached by the photovoltaic material is cooled down by water flowing underneath the receiver. Thus, both electrical and thermal power are available for multigeneration applications. Fig. 2 shows the overall conversion efficiency of the miniature system for the production of electricity, heat and CHP. The values in the Fig are for a miniature system with a reflector of $1 \mathrm{~m} 2$ aperture area, under normal beam insolation of $900 \mathrm{~W} / \mathrm{m} 2$. The coolant outlet temperature To is used as a free parameter and can be adjusted in a physical system by changing the coolant flow rate. The PV cell temperature is typically about $10^{\circ} \mathrm{C}$ higher than the coolant outlet temperature. PV cells are usually operated at temperatures below $100^{\circ} \mathrm{C}$. The Fig also shows temperature ranges for potential thermal applications. The system is under construction by a Israeli Company and adopts also a sun tracking system for each single device.

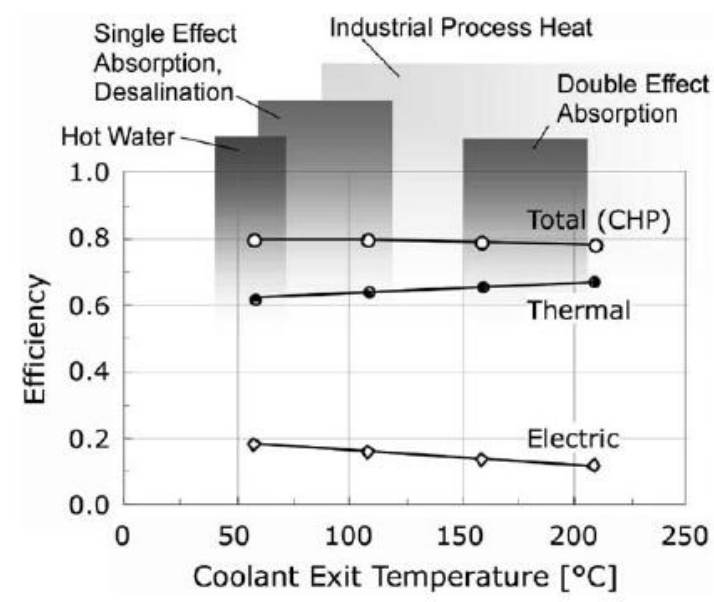

Fig. 2. Variation of the CPVT system efficiency according with the application, versus coolant temperature [3].

The evaluation of the multigeneration output can be calculated for a given radiation power Qinc as shown in the following.

The electric power is deduced by:

$$
Q_{e l}=\left(Q_{i n c} \cdot \eta_{o p t} \cdot \eta_{p v}-Q_{p a r}\right) \cdot \eta_{i n v}
$$

where:

$Q_{\text {inc }}$ [W]: is the radiation power hitting the receiver, $\eta_{\text {opt }}$ : is the efficiency of the optics,

$\eta_{P V}:$ is the $P V$ module efficiency,
$Q_{\text {par }}$ [W]: is the parasitic power needed for ancillary components consuming low energy (pumps, tracking motors), $\eta_{\text {inv }}:$ is the efficiency of the DC/AC inverter.

The cell efficiency is dependent on the concentration ratio $C$ and the cell temperature $T C$ as below summarized:

$$
\begin{array}{r}
\eta_{c}=0.298+0.0142 \cdot \ln C+(-0.000715+0.0000697 \\
\ln C \cdot\left(T C-25^{\circ} C\right)
\end{array}
$$

The PV module efficiency is then:

$$
\eta_{p v}=\eta_{c} \cdot \eta_{\bmod }
$$

where $\eta_{\text {mod }}$ is the module efficiency.

The thermal power $Q_{t h}$ achievable by the receiver can be evaluated as:

$$
Q_{t h}=Q_{i n c} \cdot \eta_{o p t}\left(1-\eta_{p v}\right)
$$

A Simulink model based on the previous equations has been implemented.

\section{B. Absorbption Machine}

The absorbtion machine is a special type of chiller using thermal energy instead of mechanical energy in order to change the physical state of the refrigerant during the refrigeration cycle. The absorbption machine requires the interaction of two (or more) substances so that the chilling effect can take place. The most used working fluids are Water/NH3 and LiBr/water. In a Lithium Bromide Absorbing Machine (LBAM) water is the refrigerant and the lithium bromide is the so called absorber. A single-effect absorption machine, in its basic form, is composed by the following components:

Generator: where a thermal input is introduced in order to vaporise the water out from the initial solution of lithium bromide and water.

Condenser: where the refrigerant vapour coming from the generator is condensed to be sent to the evaporator.

Evaporator: where the chilling effect takes place. The refrigerant evaporates in conditions of low pressure and temperature.

Absorber: where presence of a solution rich in lithium bromide allows the initial solution to be recomposed. The latter is then sent to the generator where the cycle starts again.

The cycle of a Lithium Bromide absorber machine is sketched in Fig. 3.

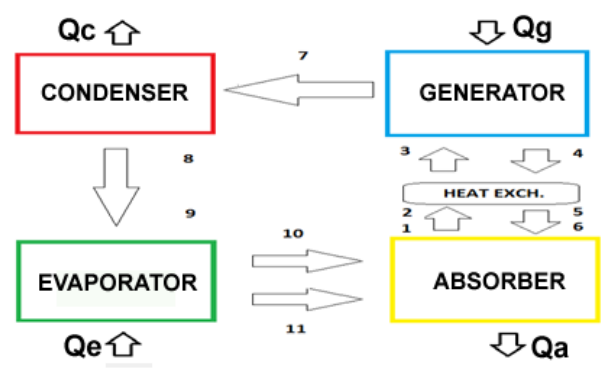

Fig. 3. Cycle of a lithium bromide absorber machine.

A steady-state model has been developed according to equations describing the energy and mass flow balance in the 
different LBAM components [5]-[8]. Knowing the values of the enthalpy $[\mathrm{kJ} / \mathrm{kg}]$ and the mass flow rate $[\mathrm{kg} / \mathrm{s}]$ in the various points of the cycle, it is possible to calculate the input and output power of the various components. Once the enthalpy values at all ports connected to the components are known, the mass flow of the refrigerant and the energy flows at the various components of the system can be determined.

\section{Application: System Layout AND Sizing}

Fig. 4 shows a simple scheme of the system. The system is meant to supply power enough to satisfy the load demand of the server room of a company located at the last floor of a building with the possibility to use the roof to install the CPVT.

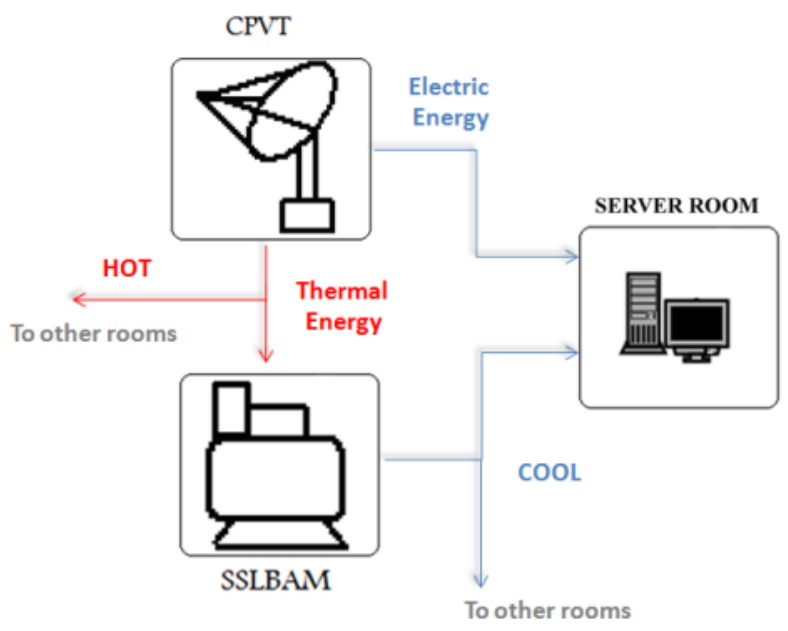

Fig. 4. Layout of the trigeneration system.

The company is characterized by using the file server, the application server and the data centre of the computer room only locally and in well defined fixed times (working hours from $7 \mathrm{am}$ to $18 \mathrm{pm}$ ). In this application the servers can be turned off at night and on the weekends. Thanks to this simple energy management, it is possible to avoid the cooling of the server room, reducing of about $50 \%$ the server power consumption. The CPVT is concerned with the thermal and electrical power generation. The thermal energy is transferred to the water flowing of the SSLBAM generator's heat exchanger. If an excessive temperature is reached, part of the water flow can be diverted to other users (e.g rooms in the same building). The generated electrical power is used to feed the server room directly. The SSLBAM unit has been chosen as the Computer Room Air Conditioning (CRAC) equipment, responsible of cooling the EDP. The cooling power generated by the SSLBAM is used to cool the server room and possibly other adjacent rooms. The developed model described in paragraph II has been used to evaluate the input power Qg required by the SSLBAM generator. In order to run the simulation, the load demand data and the weather data are needed.

The system is designed to supply power to a site located in Lisbon; Table I shows meteorological data of the chosen site.
TABLE I: METEOROLOGICAL DATA OF LisBon.

\begin{tabular}{lccc}
\hline Month & $\begin{array}{c}\text { Irradiation on } \\
\text { horizontal plane } \\
\text { (Wh/m } \mathbf{m}^{2 / d a y)}\end{array}$ & $\begin{array}{c}\text { Temperature } \\
\left(\boldsymbol{C}^{\circ}\right)\end{array}$ & $\begin{array}{c}\text { Relative } \\
\text { humidity } \\
(\%)\end{array}$ \\
\hline January & 2130 & 11 & 80 \\
February & 2710 & 12 & 78 \\
March & 4350 & 15 & 71 \\
April & 5060 & 16 & 69 \\
May & 6120 & 19 & 66 \\
June & 6880 & 23 & 66 \\
July & 7030 & 25 & 63 \\
August & 6400 & 24 & 61 \\
September & 5050 & 23 & 67 \\
October & 3570 & 18 & 72 \\
November & 2270 & 15 & 77 \\
December & 1900 & 12 & 79 \\
\hline
\end{tabular}

A typical daily electric load demand for the server room is shown in Fig. 5.

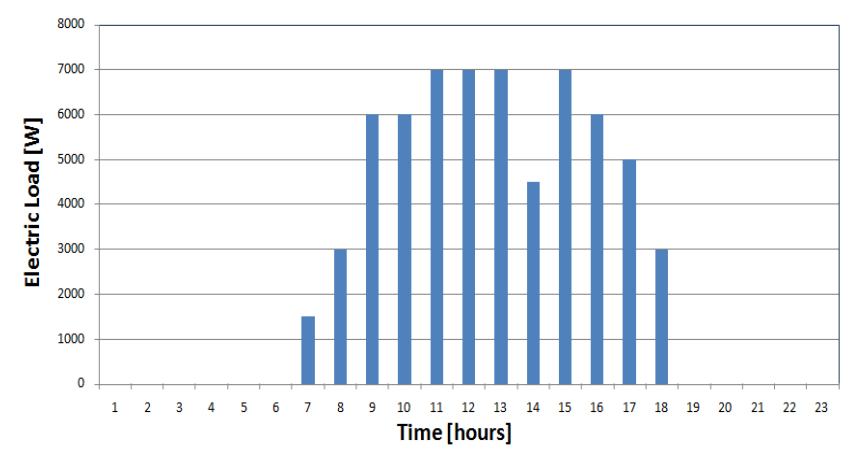

Fig. 5. Typical daily load demand.

TABLE II: PARAMETERS CHARACTERIZING THE SYSTEM AND THE SITE.

\begin{tabular}{|c|c|c|}
\hline Parameter & Value & Unit \\
\hline \multicolumn{3}{|l|}{ Server } \\
\hline Number of servers per rack & 20 & $\mathrm{~N}^{\circ}$ \\
\hline Number of racks & 2 & $\mathrm{~N}^{\circ}$ \\
\hline Dual Processor Power (@1.75V DC) & 60 & $\mathrm{~W}$ \\
\hline $\begin{array}{l}\text { Mother Board, PCI Card, DDR Memory and } \\
\text { Other Peripheral DC Power Consumption } \\
\text { (@ 12V, 5V and 3.3V DC) }\end{array}$ & 60 & $\mathrm{~W}$ \\
\hline \multicolumn{3}{|l|}{ IT Converters Power Conversion Efficiency } \\
\hline DC/DC Voltage Regulator Module (12V-1.75V) & 84 & $\%$ \\
\hline $\mathrm{DC} / \mathrm{DC}(48 \mathrm{~V}-12 \mathrm{~V})$ & 95 & $\%$ \\
\hline $\mathrm{DC} / \mathrm{DC}(48 \mathrm{~V}-5 \mathrm{~V} / 3.3 \mathrm{~V})$ & 90 & $\%$ \\
\hline Nextek Power Module (AC/DC Rectifier) & 92 & $\%$ \\
\hline \multicolumn{3}{|l|}{ Miniature Concentrating Photovoltaic } \\
\hline Reflector aperture area & 1 & $\mathrm{~m} 2$ \\
\hline Coolant Exit Temperature & 90 & $\mathrm{C}^{\circ}$ \\
\hline Electric efficiency & 0,18 & $\%$ \\
\hline Thermal efficiency & 0,62 & $\%$ \\
\hline Electric Nominal Power & 180 & $\mathrm{~W}$ \\
\hline Thermal Nominal Power & 620 & $\mathrm{~W}$ \\
\hline Number of generators & 54 & $\mathrm{~N}^{\circ}$ \\
\hline Total Nominal Electric Power & 9720 & $\mathrm{~W}$ \\
\hline Total Nominal Thermal Power & 33480 & $\mathrm{~W}$ \\
\hline \multicolumn{3}{|l|}{ Absorber Machine } \\
\hline Cooling Capacity & 20 & $\mathrm{~kW}$ \\
\hline Evaporator temperature & 6 & ${ }^{\circ} \mathrm{C}$ \\
\hline Generator solution exit temp & 90 & ${ }^{\circ} \mathrm{C}$ \\
\hline Weak solution mass fraction & 55 & $\% \mathrm{LiBr}$ \\
\hline Strong solution mass fraction & 60 & $\% \mathrm{LiBr}$ \\
\hline Solution heat exchanger temperature & 65 & ${ }^{\circ} \mathrm{C}$ \\
\hline Generator vapour exit temperature & 85 & ${ }^{\circ} \mathrm{C}$ \\
\hline \multicolumn{3}{|l|}{ General Information } \\
\hline Location & \multicolumn{2}{|l|}{ Lisbon } \\
\hline Latitude & \multicolumn{2}{|c|}{$38^{\circ} 43^{\prime \prime}$ North } \\
\hline Longitude & \multicolumn{2}{|c|}{$9^{\circ} 9^{\prime \prime}$ West } \\
\hline Elevation & \multicolumn{2}{|c|}{$95 \mathrm{~m}$ a.s.1 } \\
\hline
\end{tabular}


The total heat output that needs to be cooled down is the sum of the heat outputs of all the components, lighting, and people in the room. Generally, servers and other IT products run on low-voltage DC requiring multiple AC-DC-AC conversion that results in an overall system efficiency of AC-DC lower than $50 \%$. In order to reduce the number of conversion process, a DC-based powering architecture has been considered to obtain a better overall system efficiency. Calculations are based on typical power budget for a Dual 2.4 $\mathrm{GHz}$ Xeon Processor based 1U Server Rack.

The parameters characterizing the server room, the converters, the CPVT and the SSLBAM are summarized in Table II.

\section{Simulation RESUlts Under DifFERENT SCENARIOS}

Daily irradiation curves of a building located in Lisbon have been determined in two different months of the year (August and January). Cooling, electricity and thermal power are the values obtained by the CPVT and SSLBAM developed models. The load is represented by the cooling and electric power required by the server room. The required cooling is an input to the SSLBAM model; the generator power demand is thus determined and compared with the CPVT thermal output. Results of the simulations are illustrated in Figs. 6-9. Fig. 6 and Fig. 8 show the electrical power provided by the CPVT on an average day in August and January, respectively (the electricity demand is the same in the two scenarios).

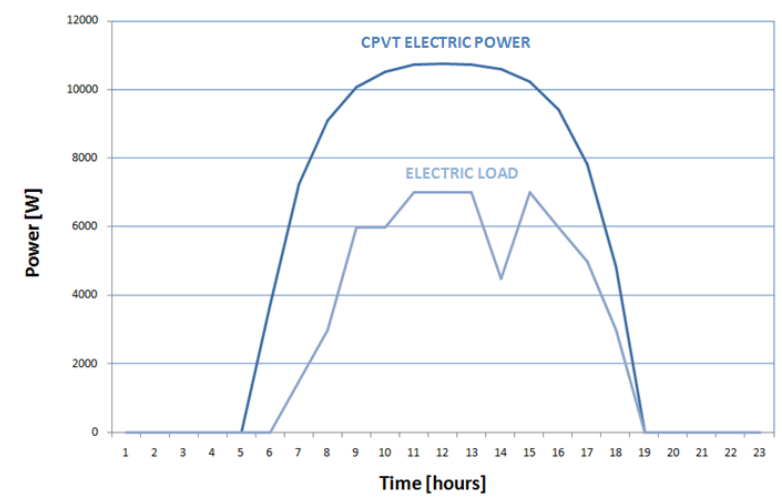

Fig. 6. Electric power provided by the CPVT in August.

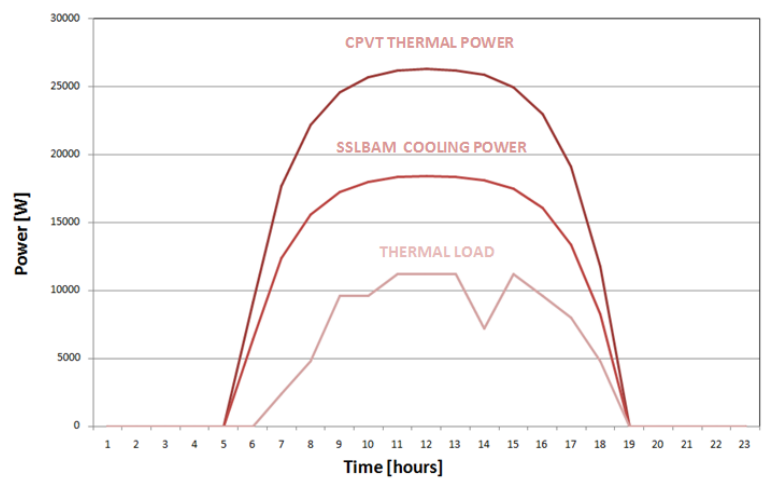

Fig. 7. Thermal power provided by the CPVT, cooling power provided by the SSLBAM and thermal load in August.

Fig. 7 and Fig. 9 show the thermal power provided by the CPVT, the cooling power provided by the SSLBAM and the required thermal load in an average day in August and January, respectively (it is assumed that the total thermal load of the server room is approximately $60 \%$ more than the electrical IT load in summer time and $40 \%$ in winter time). In August, both the electrical and thermal power curves cover the thermal and electrical loads required to supply and cool the server room. The surplus power can be used to supply adjacent rooms. In January, in the final hours of the afternoon the power curves do not cover the loads for at least 2 hours and during this period the equipments need to be supplied by the grid. All the electrical power provided by the CPVT is used to supply the equipments while the surplus thermal power can be used to supply other rooms.

\section{Conclusions}

Results of the simulations show that trigeneration using CPVT has some potentials in supplying non residential buildings having a proper available surface on rooftop. During the daily hours of the two reference periods of the year, the CPVT can partially cover the thermal and electrical demand, reducing the activation of fossil fuel consuming equipment dramatically. The system can be used for small networks or sub-networks that may not need to be available outside of business hours or may not always need to be fully operational. Further analysis will be carried out in order to investigate the integration with other components and the economic aspects concerning the various equipments and the managing cost in comparison with traditional power sources. IT equipment energy costs are strongly affected by the cooling costs that can be as much as twice those of the actual IT equipment, depending on the PUE (power usage effectiveness) of the server room. A best practice management of power and cooling issues can enable and improve reliability in particular environments, increase servers capacity and efficiency, and reduce energy costs.

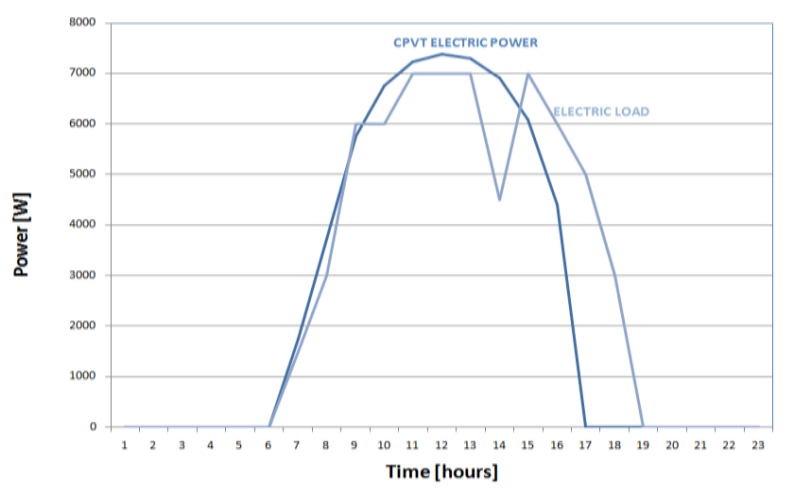

Fig. 8. Electric power provided by the CPVT in January.

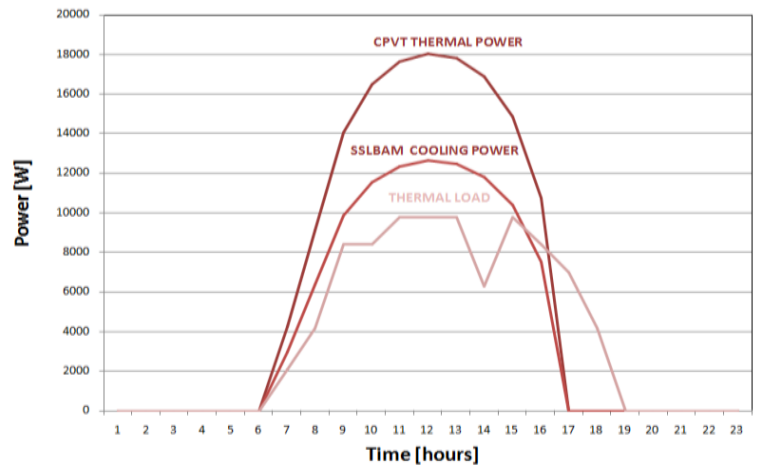

Fig. 9. Thermal power provided by the CPVT, cooling power provided by the SSLBAM and thermal load in January. 


\section{ACKNOWLEDGMENT}

This work was supported in part by the Portuguese Foundation for Science and Technology (FCT) under Project No. SFRH/BPD/46224/2008, Project No. SFRH/BPD/65591/2009 and Project No. PTDC/EEAEEL/114846/2009.

\section{REFERENCES}

[1] J. Scaramella and M. Healey, "Service-based approaches to improving data center thermal and power efficiencies," HP White Paper, May 2007.

[2] E. P. Agency, EPA Report to Congress on Server and Data Center Energy Efficiency, September 2010

[3] A. Kribus, D. Kaftori, G. Mittelman, A. Hirshfeld, Y. Flitsanov, and A. Dayan, "A miniature concentrating photovoltaic and thermal," Energy Conversion and Management, vol. 47, no. 20, pp. 3582-3590, December 2006.

[4] G. Mittelman, A. Kribus, and A. Dayan, "Solar cooling with concentrating photovoltaic/thermal (CPVT) systems," Energy Conversion and Management, vol. 48, no. 9, pp. 2481-2490, September 2007.

[5] ASHRAE, Handbook of Fundamentals. Atlanta, 1997.

[6] R. J. Lee, R. M. D. Guilio, S. M. Jeter, and A. S. Teja. "Properties of lithium bromide-water solutions at high temperatures andconcentration. II. Density and viscosity," ASHRAE Trans, vol. 96, pp. 709-28, March 1990.

[7] E. K. Herold, R. Radermacher, and S. A. Klein, Absorption Chillers and Heat Pumps, CRS press, 1996.

[8] G. A. Florides, S. A. Kalogirou, S. A. Tassou, and L. C. Wrobel, "Design and construction of a $\mathrm{LiBr}$-water absorption machine," Energy Conversion and Management, vol. 44, no. 15, pp. 2483-2508, September 2003.

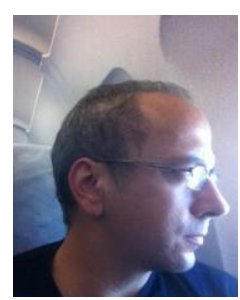

L. Petrucci received his $\mathrm{PhD}$ in Electrical Engineering in 2010 from the "Sapienza" University of Rome (Italy) and at present he is a Post Doc researcher at the Instituto de Telecomunicações, Department of Electrical and Computer Engineering, University of Coimbra. His research deals with CHCP (Trigeneration), Renewable Energy System Control, Economic Assessment of Polygeneration Systems, Mathematical Modeling and Heuristic Optimization Techniques.

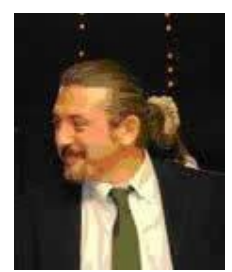

Gianluca Fabbri holds a Laurea degree in Electrical Engineering ("Sapienza" University of Rome) and a double European $\mathrm{PhD}$ in Electrical Engineering ("Sapienza" University of Rome and Madrid Polytechnic University). His research interests mainly regard Sustainable Mobility, components for stationary applications and simulation of Stand Alone Power Systems.

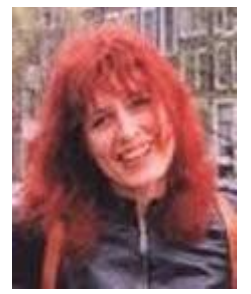

C. Boccaletti (M'04) was born in Bologna (Italy) in 1967. She received the Laurea degree in Mechanical Engineering and the $\mathrm{PhD}$ degree in Energetics from Sapienza University of Rome (Italy) in 1991 and 1995, repectively. In 1998 she was the recipient of the National Award "Energy and Environment" for her $\mathrm{PhD}$ thesis. She is an assistant professor at the Department of Astronautics, Electrical and Energetic Engineering of the Sapienza University of Rome. Her current research interests include design, analysis and optimisation of electrical machines, condition monitoring and diagnostics of electrical machines and drives, and systems based on renewable energies. She is co-author of two books and author of about 80 published papers in technical journals and conference proceedings.

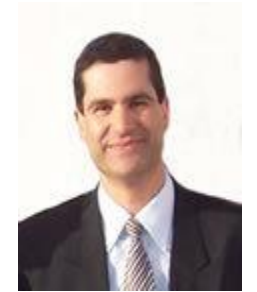

A. J. Marques Cardoso (S'89, A'95, SM'99) was born in Coimbra, Portugal, in 1962. He received the E. E. diploma, the Dr. Eng. degree and the Habilitation degree, all from the University of Coimbra, Coimbra, Portugal, in 1985, 1995 and 2008, respectively. From 1985 until 2011 he was with the University of Coimbra, where he was Director of the Electrical Machines Laboratory. Since 2011 he has been with the University of Beira Interior (UBI), Covilhã, Portugal, where he is a Full Professor at the Department of Electromechanical Engineering. His research interests are focused on condition monitoring and diagnostics of electrical machines and drives. He is the author of a book entitled Fault Diagnosis in Three-Phase Induction Motors (Coimbra, Portugal: Coimbra Editora, 1991), (in Portuguese) and more than 250 papers published in technical journals and conference proceedings. 